Article

\title{
The Novel Phosphatidylinositol-3-Kinase (PI3K) Inhibitor Alpelisib Effectively Inhibits Growth of PTEN-Haploinsufficient Lipoma Cells
}

\author{
Anna S. Kirstein 1®D, Adrien Augustin ${ }^{1,2}$, Melanie Penke ${ }^{1}$, Michele Cea ${ }^{3,4} \oplus$, Antje Körner ${ }^{1}$, \\ Wieland Kiess ${ }^{1}$ and Antje Garten ${ }^{1,5, *(D)}$ \\ 1 Pediatric Research Center, University Hospital for Children and Adolescents, Leipzig University, \\ 04103 Leipzig, Germany; anna.kirstein@medizin.uni-leipzig.de (A.S.K.); \\ adrien.augustin@student.uliege.be (A.A.); melanie.penke@medizin.uni-leipzig.de (M.P.); \\ antje.koerner@medizin.uni-leipzig.de (A.K.); wieland.kiess@medizin.uni-leipzig.de (W.K.) \\ 2 Faculty of Medicine, University of Liège, 4000 Liege, Belgium \\ 3 Chair of Hematology, Department of Internal Medicine (DiMI), University of Genoa, 16100 Genoa, Italy; \\ michele.cea@unige.it \\ 4 IRCCS Polyclinic Hospital San Martino, 16100 Genoa, Italy \\ 5 Institute of Metabolism and Systems Research, University of Birmingham, Birmingham B15 2TT, UK \\ * Correspondence: antje.garten@medizin.uni-leipzig.de; Tel.: +49-341-9726504
}

Received: 9 September 2019; Accepted: 15 October 2019; Published: 17 October 2019

check for updates

\begin{abstract}
Germline mutations in the tumor suppressor gene PTEN cause PTEN Hamartoma Tumor Syndrome (PHTS). Pediatric patients with PHTS frequently develop lipomas. Treatment attempts with the mTORC1 inhibitor rapamycin were unable to reverse lipoma growth. Recently, lipomas associated with PIK3CA-related overgrowth syndrome were successfully treated with the novel PI3K inhibitor alpelisib. Here, we tested whether alpelisib has growth-restrictive effects and induces cell death in lipoma cells. We used PTEN-haploinsufficient lipoma cells from three patients and treated them with alpelisib alone or in combination with rapamycin. We tested the effect of alpelisib on viability, proliferation, cell death, induction of senescence, adipocyte differentiation, and signaling at 1-100 $\mu \mathrm{M}$ alpelisib. Alpelisib alone or in combination with rapamycin reduced proliferation in a concentrationand time-dependent manner. No cell death but an induction of senescence was detected after alpelisib incubation for $72 \mathrm{~h}$. Alpelisib treatment led to a reduced phosphorylation of AKT, mTOR, and ribosomal protein S6. Rapamycin treatment alone led to increased AKT phosphorylation. This effect could be reversed by combining rapamycin with alpelisib. Alpelisib reduced the size of lipoma spheroids by attenuating adipocyte differentiation. Since alpelisib was well tolerated in first clinical trials, this drug alone or in combination with rapamycin is a potential new treatment option for PHTS-related adipose tissue overgrowth.
\end{abstract}

Keywords: mTOR; AKT; PHTS; PROS; lipoma; rapamycin; overgrowth; proliferation; spheroids; ribosomal protein $\mathrm{S} 6$

\section{Introduction}

Patients with germline mutations in the tumor suppressor gene PTEN show a wide variety of phenotypes related to cellular overgrowth. There are several syndromes associated with PTEN mutations, including Cowden syndrome, Proteus syndrome, and Bannayan-Riley-Ruvalcaba syndrome (BRRS), all subsumed under the term PTEN Hamartoma Tumor Syndrome (PHTS) [1]. Symptoms include an increased risk for cancer (breast, endometrial, thyroid), macrocephaly, vascular malformations, polyps of the gastrointestinal tract and other hamartomas, and, especially in the BRRS 
type, early-onset lipoma development [2]. Lipomatosis in pediatric patients can be life-threatening, as the infiltrating growth of lipomatous masses can obstruct vital organ function and can lead to chronic pain conditions. In some patients, resection as the only current treatment option is impossible due to lipoma position or poor general condition of the patient. Treatment attempts with the mechanistic target of rapamycin complex 1 (mTORC1) inhibitor rapamycin were shown to improve the general condition of PHTS patients [3,4], but could not reverse lipoma growth [4]. PTEN antagonizes the phosphoinositide-3-kinase (PI3K)/AKT/mTOR signaling pathway which regulates cellular metabolism and promotes cellular growth, proliferation, and survival [5]. PI3K lies downstream of several growth factor receptors and upon activation catalyzes the reaction of phosphatidylinositol $(4,5)$-bisphosphate $\left(\mathrm{PIP}_{2}\right)$ to phosphatidylinositol $(3,4,5)$-trisphosphate $\left(\mathrm{PIP}_{3}\right) . \mathrm{PIP}_{3}$ is the key molecule to activate further downstream signaling components, e.g., the pro-survival molecule AKT. PTEN acts as a lipid phosphatase on $\mathrm{PIP}_{3}$, catalyzing the conversion to $\mathrm{PIP}_{2}$, and therefore is a negative regulator of the AKT/mTOR signaling cascade [6]. mTORC1 regulates AKT activity through a negative feedback loop via its target ribosomal protein $\mathrm{S} 6$ kinase. An inhibition of $\mathrm{mTORC} 1$ by rapamycin leads to an increased activation of AKT [7]. This loss of negative feedback inhibition of AKT might be a cause for the reduced efficacy of rapamycin observed in a treatment attempt of a child with PHTS-associated lipoma [4].

Recently, patients with lipomatous tumors associated with a related spectrum of syndromes caused by mosaic activating PI3K mutations (PIK3CA-related overgrowth syndrome, PROS) were successfully treated with the novel PI3K inhibitor alpelisib (BYL-719) [8]. The size of patients' tumors was reduced after few months and side effects were reported to be manageable. Alpelisib is a selective $\mathrm{PI} 3 \mathrm{~K} \alpha$ inhibitor designed for the use in human cancer therapy [9]. It was tested in several clinical trials alone or in combination with other chemotherapeutics against solid tumors [10-12]. Here, we tested proliferation, induction of apoptosis, and signaling pathway activation in two-dimensional (2D) and three-dimensional (3D) cultures of PTEN-haploinsufficient primary lipoma cells treated with alpelisib. We aimed to determine whether alpelisib has growth-restrictive effects and would induce cell death in lipoma cell cultures from pediatric patients with PHTS.

\section{Results}

\subsection{Effect of Alpelisib on Proliferation of Lipoma Cells}

\subsubsection{Alpelisib Reduced Cell Viability in a Dose- and Time-Dependent Manner}

We treated five different primary lipoma cell cultures with alpelisib concentrations ranging from 1 to $50 \mu \mathrm{M}$ and measured cell viability (the number of metabolically active cells) using the WST-1 assay after $72 \mathrm{~h}$ for alpelisib alone (Figure 1a) or in combination with $10 \mathrm{nM}$ rapamycin (Figure 1b). Additionally, we tested cell viability at different time points (24-144 h) in LipPD1 cells for alpelisib alone (Figure 1c) and in combination with rapamycin (Figure 1d).

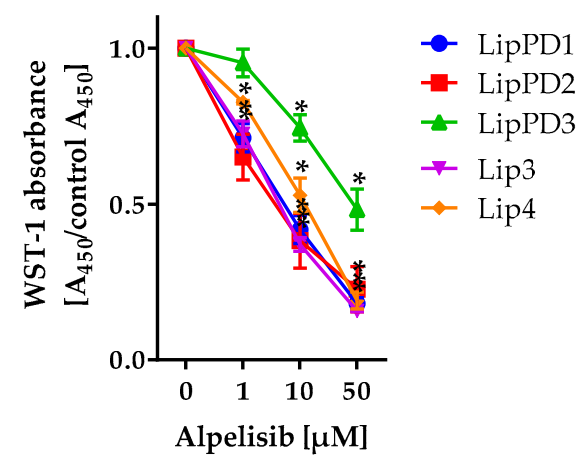

(a)

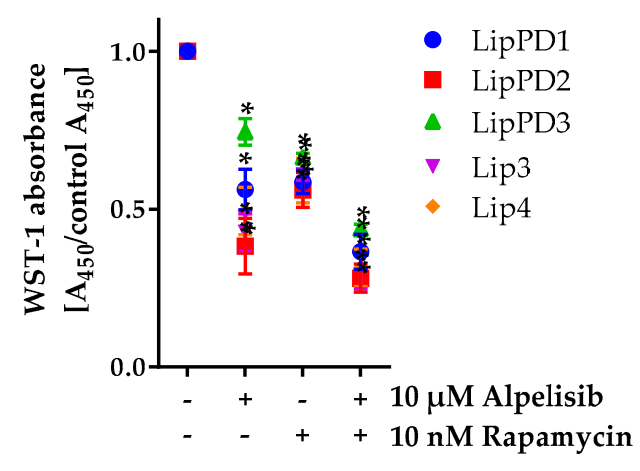

(b)

Figure 1. Cont. 


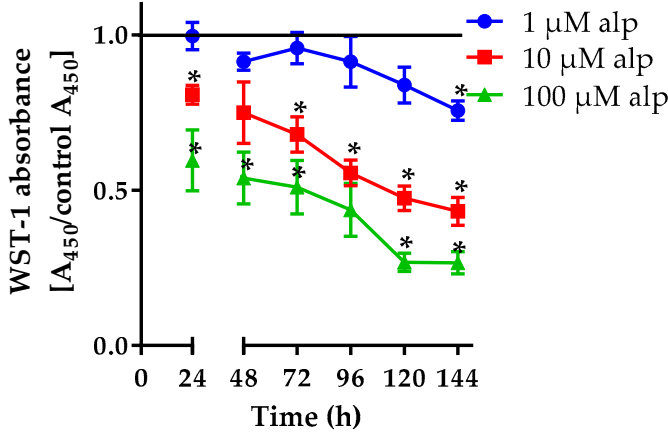

(c)

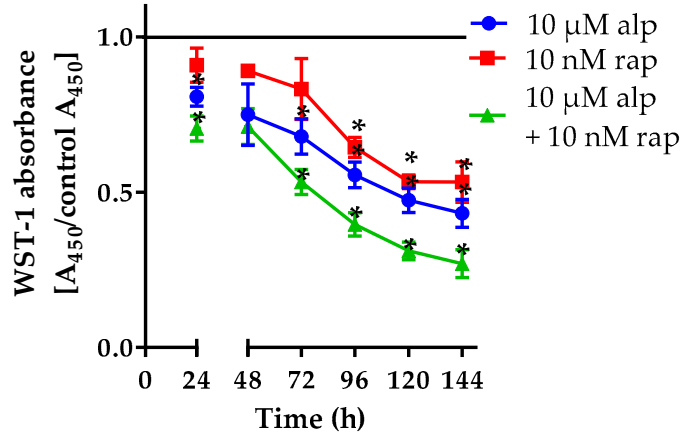

(d)

Figure 1. WST-1 cell viability assay after alpelisib or alpelisib+rapamycin treatment of lipoma cell cultures from three PTEN Hamartoma Tumor Syndrome (PHTS) patients (LipPD1-3) and two PIK3CA-related overgrowth spectrum (PROS) patients (Lip3-4): (a) $72 \mathrm{~h}$ alpelisib treatment reduced cell viability at concentrations $\geq 10 \mu \mathrm{M}$ in all tested cell cultures; (b) a $72 \mathrm{~h}$ combined treatment with alpelisib and rapamycin further decreased cell viability; (c) 24-144 h treatment of PTEN-haploinsufficient LipPD1 cells at 1 to $100 \mu \mathrm{M}$ alpelisib reduced cell viability; (d) 24-144 h combined treatment with alpelisib and/or rapamycin further decreased viability. Fold over solvent control (black line), $n=3{ }^{*} p \leq 0.05$.

We noted a concentration-dependent decrease in cell viability for all cell cultures $(p<0.0001)$. At $10 \mu \mathrm{M}$ alpelisib, cell viability was significantly decreased in all cell cultures. A combination of $10 \mu \mathrm{M}$ alpelisib and $10 \mathrm{nM}$ rapamycin further decreased cell viability compared to single treatment $(p<0.001)$. IC 50 values for $72 \mathrm{~h}$ WST-1 assays were calculated to be $9.09 \mu \mathrm{M}$ (LipPD1), $6.31 \mu \mathrm{M}$ (LipPD2), $18.33 \mu \mathrm{M}$ (LipPD3), $6.7 \mu \mathrm{M}$ (Lip3), and $15.74 \mu \mathrm{M}$ (Lip4). A summary of all $\mathrm{IC}_{50}$ values is given in supplementary Table S1. We found similar effects for PHTS (LipPD1-3) and PROS patients' lipoma cells (Lip3 and Lip4). During six days of treatment, cell viability decreased in a concentration$(p<0.0001)$ and time-dependent manner $(p<0.0001)$. We observed a further decrease in cell viability for a combined treatment of alpelisib and rapamycin. To examine whether combining alpelisib and rapamycin has synergistic or additive anti-lipoma activity, LipPD1, LipPD2, and LipPD3 cells were treated with alpelisib and rapamycin across a range of concentrations. Analysis of the combined effect by the Chou and Talalay method [13] showed a significant decrease in viability after co-treatment compared to either agent alone, with a combination index of $<1.0$ in all tested cells. Overall, these data confirmed the synergistic anti-lipoma activity of this drug combination (supplementary Figure S1).

\subsubsection{Alpelisib Inhibited Lipoma Cell Proliferation}

To analyze whether the effects seen in the WST-1 assays are caused by an inhibition of proliferation, we counted Hoechst-stained nuclei of lipoma cells after alpelisib, rapamycin, or combined treatment (Figure 2a-d) and performed immunofluorescence staining of the proliferation marker Ki-67 in LipPD1 cells after $48 \mathrm{~h}$ alpelisib treatment (Figure 2e-f).

Alpelisib attenuated growth of all three lipoma cell cultures alone and in combination with rapamycin. For LipPD1 cells treated with $100 \mu \mathrm{M}$ alpelisib, cell count was stable for six days in culture. The same observation was made for a combination of $10 \mu \mathrm{M}$ alpelisib and $10 \mathrm{nM}$ rapamycin. $\mathrm{IC}_{50}$ values for $72 \mathrm{~h}$ Hoechst assays were calculated to be $15.91 \mu \mathrm{M}$ (LipPD1), $10.06 \mu \mathrm{M}$ (LipPD2), and $15.79 \mu \mathrm{M}$ (LipPD3) (supplementary Table S1). The fraction of Ki-67 positive cells was reduced after alpelisib treatment for $1 \mu \mathrm{M}$ to $0.75 \pm 0.07$ fold $(p=0,074)$, for $10 \mu \mathrm{M}$ to $0.55 \pm 0.06$ fold $(p=0.018)$, and for $100 \mu \mathrm{M}$ to $0.22 \pm 0.1$ fold $(p=0.017)$ in a concentration-dependent manner $(p=0.0098)$. Ki-67 immunofluorescence staining in LipPD2 and LipPD3 cells after $72 \mathrm{~h}$ also showed a reduced fraction of proliferation marker positive cells (supplementary Figure S2a). 


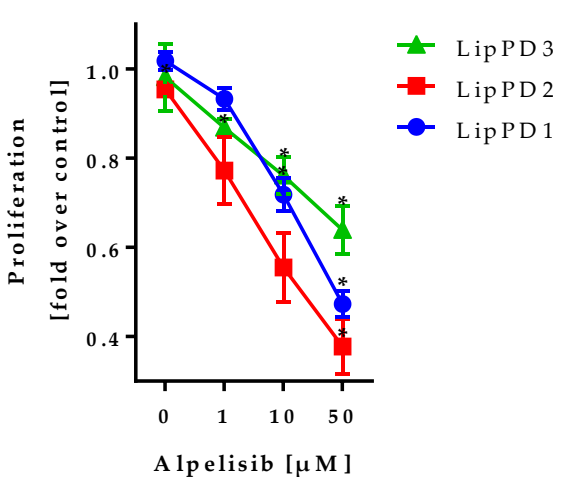

(a)

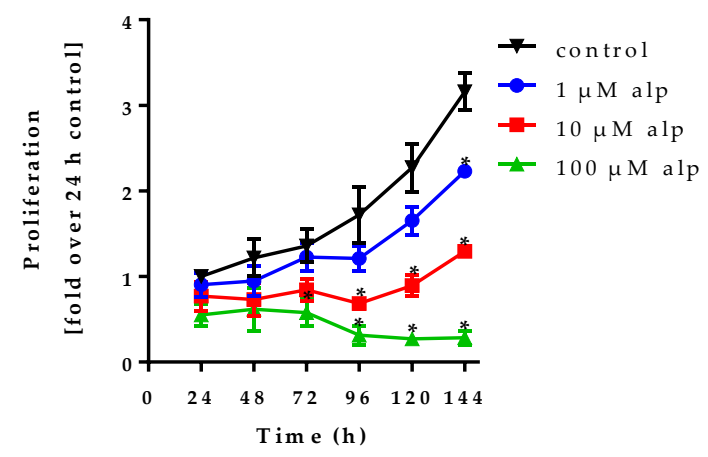

(c)

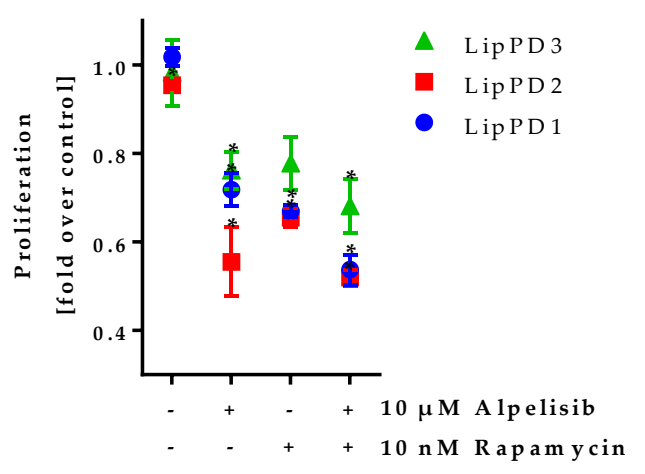

(b)

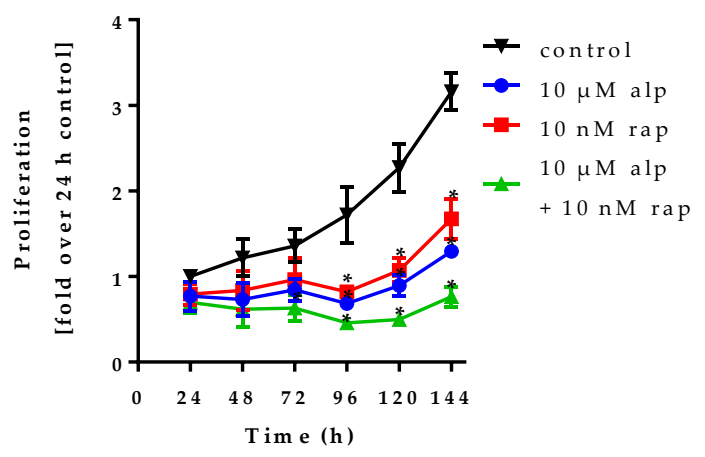

(d)

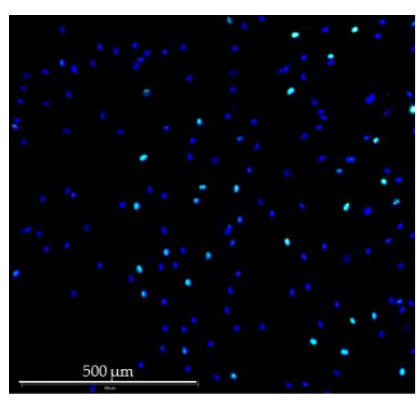

Control

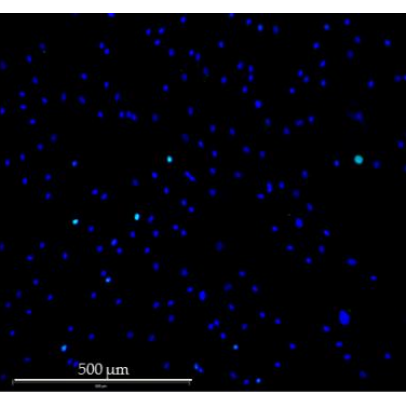

Alpelisib $10 \mu \mathrm{M}$

(e)

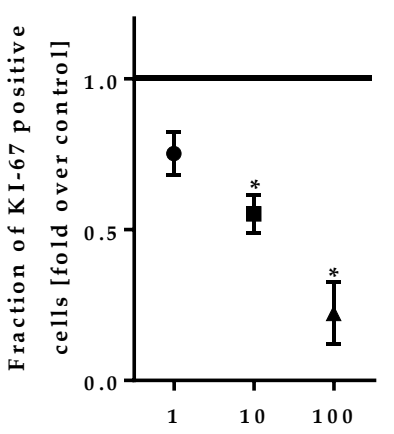

A lpelisib $[\mu \mathrm{M}]$

(f)

Figure 2. Hoechst proliferation assay and Ki-67 proliferation marker immunofluorescence staining after alpelisib/alpelisib+rapamycin treatment in PTEN-haploinsufficient lipoma cell cultures: (a) $72 \mathrm{~h}$ alpelisib treatment attenuated proliferation in a concentration-dependent manner in three different lipoma cell cultures; (b) a combined treatment with alpelisib and rapamycin further decreased cell count. Fold over solvent control, $n=3,{ }^{*} p \leq 0.05$. (c) Cell counts in LipPD1 cells during six days of $100 \mu \mathrm{M}$ alpelisib (alp) treatment did not increase, while cells in solvent control proliferated; (d) a combination of rapamycin (rap) and alpelisib further decreased proliferation compared to treatment with alpelisib or rapamycin alone. $n \geq 3, * p \leq 0.05$ compared to solvent control. (e) Ki-67 proliferation marker immunofluorescence staining of LipPD1 cells after $48 \mathrm{~h}$ of alpelisib treatment: Merged image of nuclei (blue) and Ki-67 (green) for untreated and $10 \mu \mathrm{M}$ alpelisib treated cells; (f) fraction of Ki-67 positive cells is decreased after alpelisib treatment, fold over solvent control (black line), $n=3,{ }^{*} p \leq 0.05$. 


\subsection{Cytotoxicity of Alpelisib in Lipoma Cells}

We measured apoptosis induction in lipoma cells after $72 \mathrm{~h}$ alpelisib treatment by annexin V/PI staining via flow cytometry (Figure 3a), and cell death after $24 \mathrm{~h}$ and $72 \mathrm{~h}$ via LDH-cytotoxicity assay (Figure 3b).

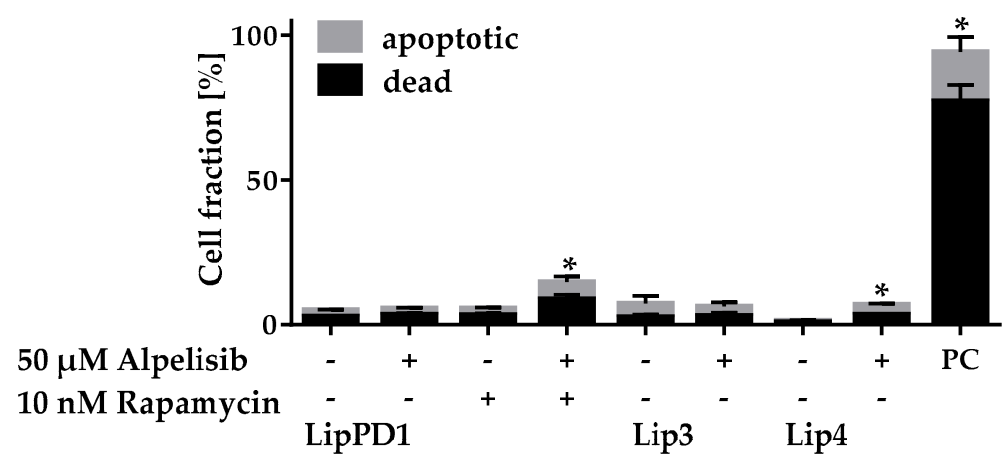

(a)

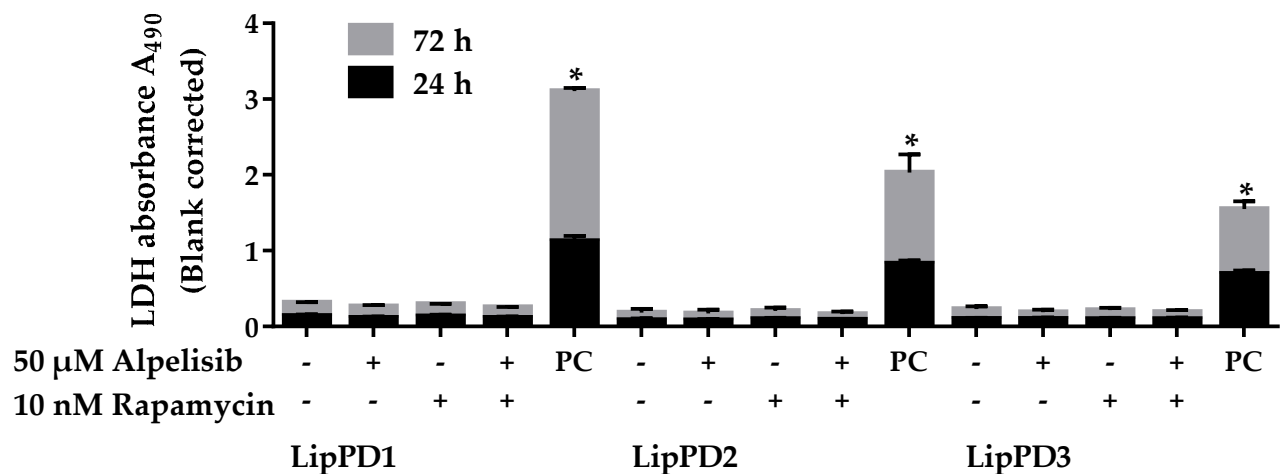

(b)

Figure 3. Apoptosis/cell death of PTEN Hamartoma Tumor Syndrome (PHTS, LipPD1-3) and PIK3CA-related overgrowth spectrum (PROS, Lip3-4) patients' lipoma cells after $50 \mu \mathrm{M}$ alpelisib and/or $10 \mathrm{nM}$ rapamycin treatment. (a) Apoptotic/dead cells determined via annexin V/PI staining did not increase compared to solvent control in LipPD1 and Lip3 cells, while $50 \mu \mathrm{M}$ perifosine (PC, positive control) led to cell death. A minor rise in the fraction of apoptotic/dead cells was observed for Lip4 and for a combination with $10 \mathrm{nM}$ rapamycin in LipPD1 cells. (b) LDH cytotoxicity assay in LipPD1-3 cells showed no increase in cell death after $24 \mathrm{~h}$ or $72 \mathrm{~h} 50 \mu \mathrm{M}$ alpelisib and/or $10 \mathrm{nM}$ rapamycin treatment. PC: Cell lysis positive control, $n=3,{ }^{*} p \leq 0.05$.

We did not observe cell death after $72 \mathrm{~h} 50 \mu \mathrm{M}$ alpelisib treatment in LipPD1 and Lip3 cells. The fraction of viable cells was slightly reduced in Lip4 cells after $50 \mu \mathrm{M}$ alpelisib treatment compared to solvent control. The fraction of dead and apoptotic cells was highly elevated in the positive control (50 $\mu \mathrm{M}$ perifosine). For LipPD1 cells, we did not observe apoptosis after $72 \mathrm{~h} 10 \mathrm{nM}$ rapamycin treatment alone, while the total fraction of apoptotic and dead cells was slightly increased (by $9.6 \pm 2.3 \%, p=0.0471$ ) after a combined treatment with alpelisib and rapamycin. To confirm our findings, we performed LDH cytotoxicity assays for LipPD1, LipPD2, and LipPD3 cells after $24 \mathrm{~h}$ and $72 \mathrm{~h}$ of $50 \mu \mathrm{M}$ alpelisib treatment (Figure $3 \mathrm{~b}$ ). We did not observe any additional LDH release in $50 \mu \mathrm{M}$ alpelisib treated lipoma cells, implying no induction of cell death. We neither observed cytotoxicity for $10 \mathrm{nM}$ rapamycin nor a combination of $50 \mu \mathrm{M}$ alpelisib with $10 \mathrm{nM}$ rapamycin. 


\subsection{Effect of Alpelisib on PI3K Signaling}

To determine whether alpelisib affects downstream PI3K signaling, we performed Western blot analyses, qPCRs, and immunofluorescence staining of alpelisib-treated LipPD1 cells to detect activated signaling components.

\subsubsection{Alpelisib Reduced PI3K/AKT/mTOR Pathway Activation in Lipoma Cells}

To determine basal pathway activation, cells were treated with alpelisib for $24 \mathrm{~h}$ and AKT, mTOR, and ribosomal protein S6 phosphorylation was determined via Western blot analysis (Figure 4a-c). pS6-immunofluorescence staining of LipPD1 cells was performed after $48 \mathrm{~h}$ alpelisib treatment (Figure 4d-e).

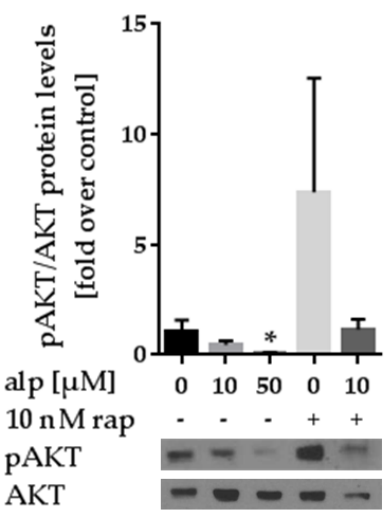

(a)

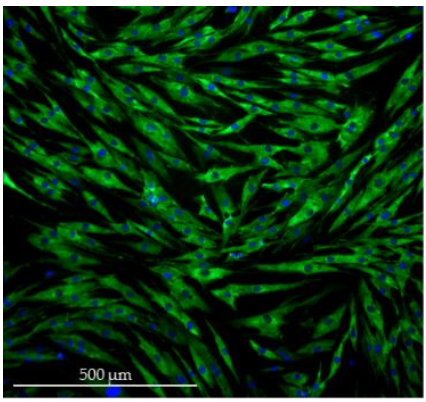

Control

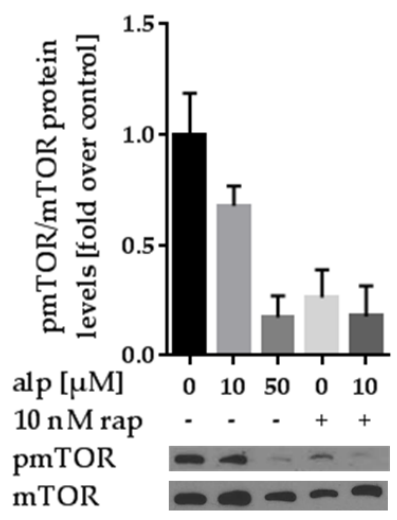

(b)

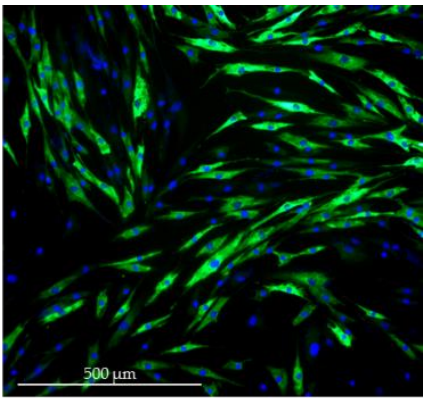

Alpelisib $10 \mu \mathrm{M}$

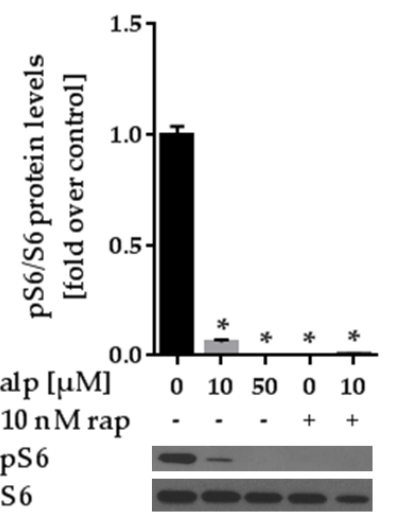

(c)

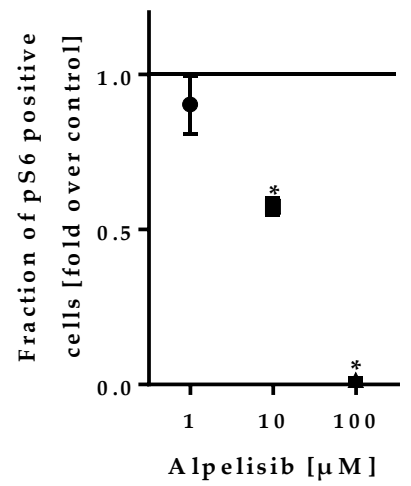

(e)

Figure 4. Western blot analysis of LipPD1 cells after $24 \mathrm{~h}$ treatment and pS6 immunofluorescence staining after $48 \mathrm{~h}$ treatment with alpelisib (alp) and/or rapamycin (rap), representative blots and densitometric analysis: (a) Phosphorylated AKT (phospho-Thr 308 (pAKT) normalized to total AKT) was reduced after alpelisib but not rapamycin treatment; (b) phosphorylation of mTOR (phospho-Ser 2448 (pmTOR) normalized to total mTOR); (c) phosphorylation of ribosomal protein S6 (phospho-Ser 235/236 (pS6) normalized to total $\mathrm{S} 6$ protein) was reduced after alpelisib and rapamycin treatment. One representative blot out of three for each protein (phosphorylated and total) and densitometric analysis of three independent experiments is shown, fold over solvent control, ${ }^{*} p \leq 0.05$. (d) Merged image of nuclei (blue) and pS6 (green) immunofluorescence staining for untreated and $10 \mu \mathrm{M}$ alpelisib-treated cells; (e) fraction of pS6 positive cells decreased after alpelisib treatment, fold over solvent control (black line), $n=3, * p \leq 0.05$.

AKT activation was reduced in $50 \mu \mathrm{M}$ alpelisib-treated cells $(p=0.019)$, while rapamycin enhanced AKT phosphorylation $(p=0.192)$. This effect of rapamycin was repressed when combined with alpelisib 
$(p=0.279)$. Activation of mTOR was reduced in $10 \mu \mathrm{M}(p=0.099)$ and $50 \mu \mathrm{M}(p=0.066)$ alpelisib-treated cells, as well as in $10 \mathrm{nM}$ rapamycin-treated cells $(p=0.18)$. Phosphorylation of $\mathrm{S} 6$ was significantly reduced for all tested alpelisib and rapamycin concentrations. Western blots for LipPD2 (supplementary Figure S3) and LipPD3 (supplementary Figure S4) cells showed similar results. All blots, GAPDH loading control blots and densitometric analyses are provided in supplementary Figures S5-S7 and supplementary Table S2-S3. In immunofluorescence staining experiments, the fraction of pS6 positive cells was reduced after alpelisib treatment for $10 \mu \mathrm{M}$ to $0.57 \pm 0.02$ fold $(p=0.0074)$ and for $100 \mu \mathrm{M}$ to $0.01 \pm 0.006$ fold $(p=0.0169)$. pS6 immunofluorescence staining in LipPD2 and LipPD3 cells after $72 \mathrm{~h}$ showed similar results (supplementary Figure S2b).

\subsubsection{Alpelisib Reduced PCNA, GLUT1, and PGK mRNA Expression}

To determine the influence of alpelisib on gene expression, we performed reverse transcription quantitative PCR (RT-qPCR) analysis for the proliferation marker PCNA, the glucose transporter GLUT1, and the glycolysis enzyme PGK (Figure 5). All three genes are known to be regulated by PI3K signaling [14-16].

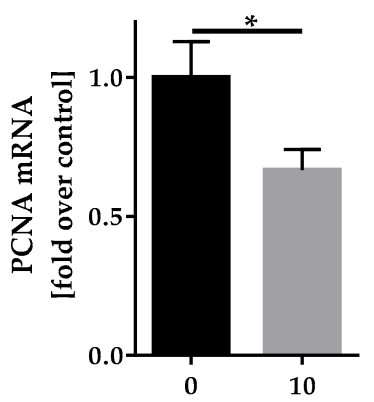

Alpelisib concentration $[\mu \mathrm{M}]$

(a)

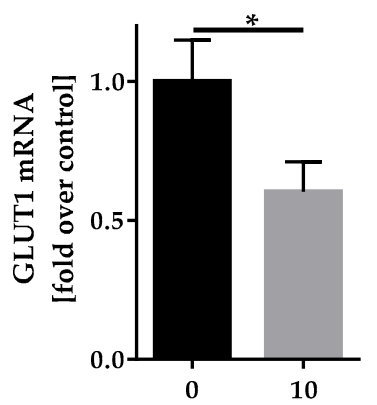

Alpelisib concentration $[\mu \mathrm{M}]$

(b)

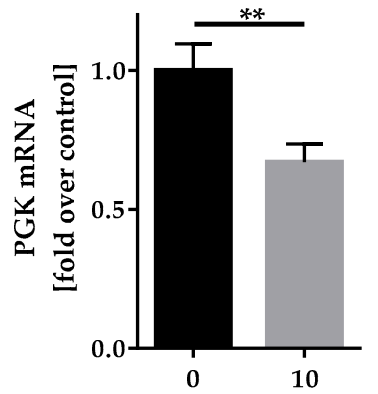

Alpelisib concentration $[\mu \mathrm{M}]$

(c)

Figure 5. RT-qPCR of cell cycle and glucose metabolism genes from LipPD1 cells after $24 \mathrm{~h}$ treatment with $10 \mu \mathrm{M}$ alpelisib: mRNA expression of (a) PCNA, (b) GLUT1, and (c) PGK was downregulated in $10 \mu \mathrm{M}$ alpelisib-treated cells. Fold over control, values were normalized to the housekeeper gene TBP, $n=6,{ }^{*} p \leq 0.05, * * p \leq 0.01$.

PCNA mRNA was downregulated after $24 \mathrm{~h}$ alpelisib treatment (to $0.67 \pm 0.08$ fold). Similarly, we observed a downregulation of GLUT1 mRNA (to $0.60 \pm 0.11$ fold) and PGK mRNA (to $0.67 \pm 0.06$ fold).

\subsection{Effect of Alpelisib on Adipocyte Differentiation in 2D and 3D Models}

To test whether alpelisib would attenuate adipogenesis, we differentiated LipPD1 cells in 2D culture and 3D spheroid models to assess lipid accumulation (Figure 6a-b), differentiation markers (2D) (Figure 6c-e), and spheroid size (3D) (Figure 6f-g).

We observed reduced lipid accumulation after alpelisib treatment of LipPD1 cells in adipocyte differentiation medium for 10 days. The fraction of adipocytes was reduced from $54.8 \pm 7 \%$ to $29.9 \pm 7 \%$. Further, we investigated the mRNA expression of differentiation markers with or without $10 \mu \mathrm{M}$ alpelisib in adipogenic medium and detected peroxisome proliferator-activated receptor $\gamma($ PPAR $\gamma)$ mRNA downregulated after 10 days in differentiation medium with $10 \mu \mathrm{M}$ alpelisib to $0.55 \pm 0.06$ fold. Adiponectin mRNA was downregulated to $0.54 \pm 0.04$ fold and adipocyte protein 2 (aP2) mRNA to $0.54 \pm 0.03$ fold. Fatty acid synthase (FASN) mRNA was downregulated as well to $0.58 \pm 0.09$ fold, $p=0.064$ (supplementary Figure S8). To confirm our findings, we evaluated the effect of alpelisib treatment on adipocyte differentiation in a 3D spheroid model [17]. While the size of control 3D-spheroids increased during in vitro differentiation (to $1.25 \pm 0.06$ fold after 10 days), the size of $10 \mu \mathrm{M}$ alpelisib-treated 
spheroids was reduced after 4 days (to $0.78 \pm 0.05$ fold) and, afterwards, stable throughout the duration of the experiment (to $0.79 \pm 0.05$ fold after 10 days). The differences between controls and alpelisib treated cells were significant from day 4 on $(p=0.0063$ at day 4$)$.

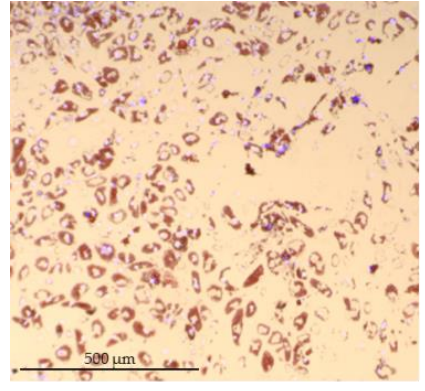

Control

(a)

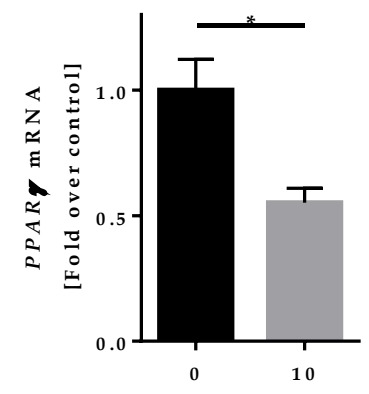

A lpelisib concentration $[\mu \mathrm{M}]$

(c)

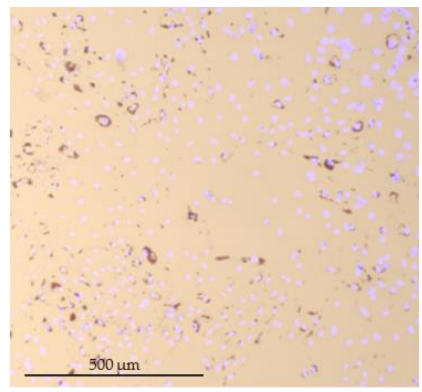

Alpelisib $10 \mu \mathrm{M}$

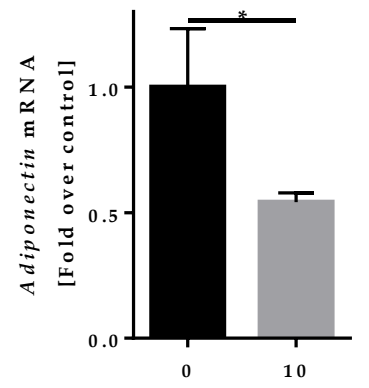

A lpelisib concen tration $[\mu M]$

(d)

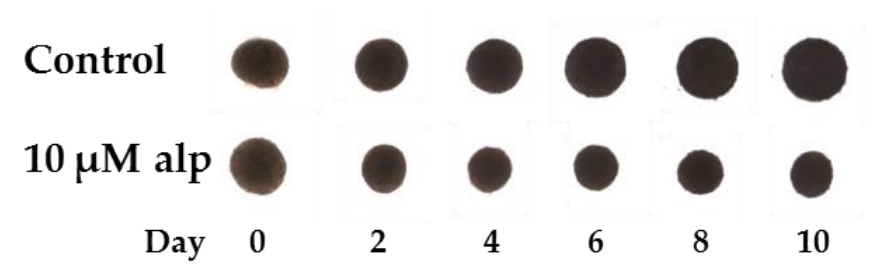

(f)

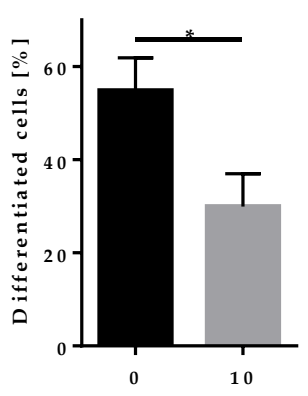

A lpelisib concentration $[\mu \mathrm{M}]$

(b)

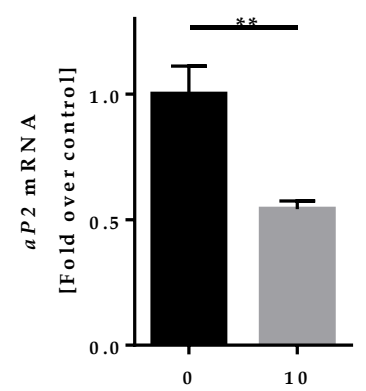

A lpelisib concentration $[\mu \mathrm{M}]$

(e)

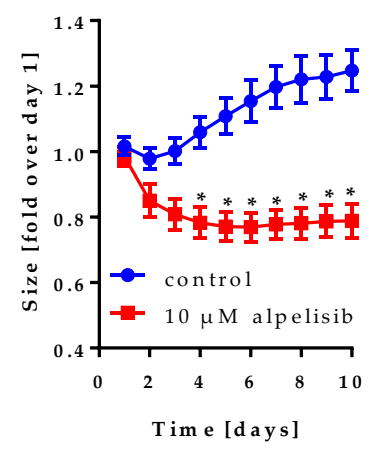

(g)

Figure 6. Alpelisib treatment of LipPD1 cells during adipocyte differentiation: (a) Oil Red O lipid (red) and Hoechst (blue) staining after 10 days in differentiation medium showed reduced lipid accumulation after $10 \mu \mathrm{M}$ alpelisib treatment; (b) the percentage of adipocytes after 10 days in differentiation medium was decreased with $10 \mu \mathrm{M}$ alpelisib (alp) compared to solvent control, $n=3,{ }^{*} p=0.016$. RT-qPCR of adipogenesis-related genes in LipPD1 cells after 10 days of differentiation with or without $10 \mu \mathrm{M}$ alpelisib: mRNA expression of (c) $P P A R \gamma$, (d) Adiponectin, and (e) $a P 2$ was downregulated in $10 \mu \mathrm{M}$ alpelisib-treated cells. Fold over control, values were normalized to the housekeeper gene $\beta$-actin, $n=3,{ }^{*} p \leq 0.05,{ }^{* *} p \leq 0.01$. (f) $10 \mu \mathrm{M}$ alpelisib treatment of 3D LipPD1 cell cultures during adipocyte differentiation; (e) size of 3D lipoma spheroids during 10 days in differentiation medium decreased with $10 \mu \mathrm{M}$ alpelisib (alp) compared to day 1, values for day 1 were calculated by normalizing to the mean of day 1 ; for following days, each spheroid size was divided by the size of the same spheroid at day $1, n=4, * p \leq 0.05$. 


\subsection{Effect of Alpelisib on Senescence of Lipoma Cells}

To check whether the lipoma cells maintained their mesenchymal stem cell phenotype or underwent senescence during alpelisib treatment, we performed a $\beta$-galactosidase senescence staining (Figure 7a-b) and measured gene expression of stem cell and senescence markers (Figure 7c-e).

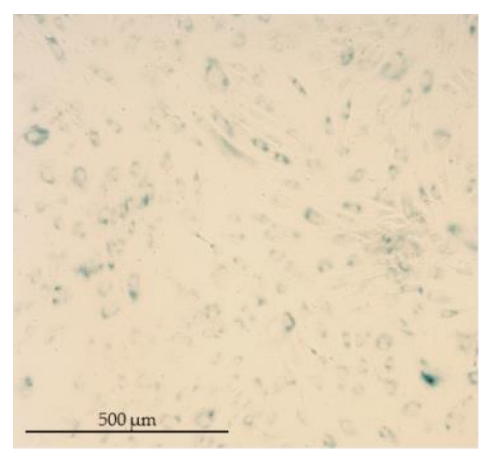

Control

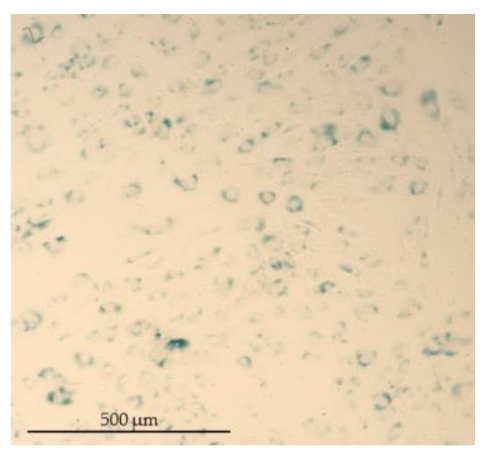

Alpelisib $10 \mu \mathrm{M}$

(a)

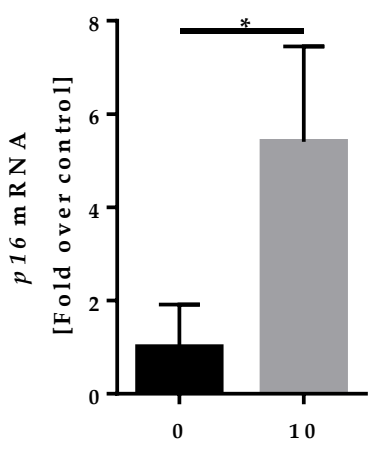

A lpelisib concentration $[\mu \mathrm{M}]$

(c)

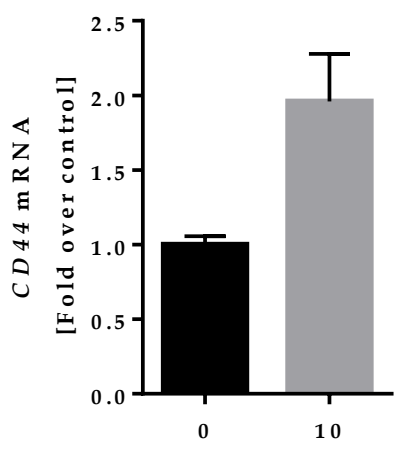

Alpelisib concentration $[\mu \mathrm{M}]$

(d)

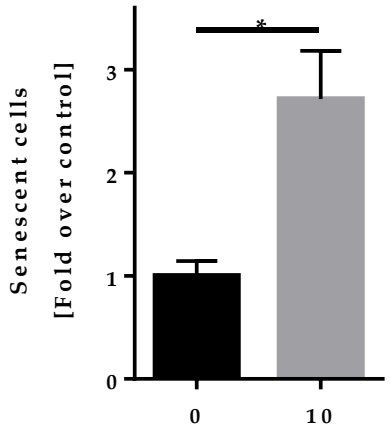

Alpelisib concentration $[\mu \mathrm{M}]$

(b)

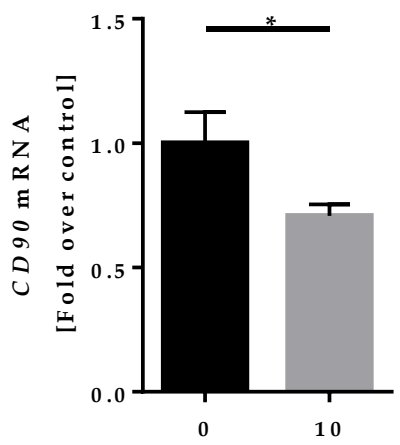

Alpelisib concentration $[\mu \mathrm{M}]$

(e)

Figure 7. $\beta$-galactosidase senescence staining of LipPD1 cells after $72 \mathrm{~h}$ alpelisib treatment: (a) $\beta$-galactosidase staining showed a higher number of senescent (blue) cells after $10 \mu \mathrm{M}$ alpelisib treatment; (b) the fraction of senescent cells increased with $10 \mu \mathrm{M}$ alpelisib compared to solvent control, $n=3, * p=0.027$. RT-qPCR of senescence and stem cell marker genes from LipPD1 cells after 10 days of differentiation with or without $10 \mu \mathrm{M}$ alpelisib: mRNA expression of (c) p16 was upregulated, (d) CD44 was upregulated ( $p=0.053)$, and (e) CD90 was downregulated in $10 \mu \mathrm{M}$ alpelisib-treated cells. Fold over control, values were normalized to the housekeeper gene $\beta$-actin, $n=3,{ }^{*} p \leq 0.05$.

The fraction of senescent cells after $72 \mathrm{~h}$ alpelisib treatment was elevated $2.71 \pm 0.47$ fold, indicating cell cycle arrest. Similar observations were made for LipPD2 $(2.43 \pm 0.7$ fold, $p=0.236)$ and LipPD3 cells $(4.96 \pm 1.98$ fold, $p=0.065)$ (supplementary Figure S9). Since we observed an inhibition of adipogenesis through alpelisib, we investigated whether these undifferentiated cells would retain their mesenchymal stem cell state or undergo senescence by analyzing the mRNA expression of senescence marker CDKN2A ( 16 ) and stem cell markers CD44 and Thy-1 (CD90) with or without $10 \mu \mathrm{M}$ alpelisib in adipogenic medium. $p 16$ mRNA was upregulated after 10 days in differentiation medium with $10 \mu \mathrm{M}$ alpelisib (to $5.4 \pm 2.05$ fold). CD44 mRNA was upregulated to $1.96 \pm 0.32$ fold. In contrast, CD90 mRNA was reduced to $0.71 \pm 0.05$ fold. Similar trends in the regulation of adiponectin, $p 16, C D 44$, and CD90 were observed in LipPD2 and LipPD3 cells (supplementary Figure S10). 


\section{Discussion}

Lipomatosis associated with germline mutations in PTEN can be a severe complication in pediatric patients. So far, the only treatment option is surgical resection, which is not feasible in every patient and has to be repeated because of lipoma recurrence. In this research work, we tested effects of the novel PI3K inhibitor alpelisib on PTEN-haploinsufficient lipoma cells (stromal-vascular fraction) from pediatric patients. Proliferation of these preadipocyte-like cells is enhanced, potentially due to a constitutive overactivation of the PI3K-pathway [18]. The PI3K/AKT/mTOR axis acts as a major growth factor signaling pathway regulating proliferation and survival [19]. In adipose tissue, PI3K signaling is essential for adipocyte differentiation [20]. We asked whether alpelisib influences these cellular responses and, by doing so, can inhibit growth of lipoma cells.

When we treated lipoma cells with alpelisib, we observed a concentration-dependent decrease in cell viability. This decrease was in line with a reduced cell number after alpelisib treatment. The fraction of proliferation marker Ki-67 positive cells was decreased in a concentration-dependent manner and the proliferation marker PCNA was downregulated on the mRNA level. While these findings indicate that alpelisib negatively influences cell proliferation of PTEN-haploinsufficient lipoma cells, apoptosis could not be induced during $72 \mathrm{~h}$ alpelisib treatment. Indeed, we did not detect any alpelisib-induced cytotoxicity in any of the cell lines tested. The number of dead/apoptotic cells was also only slightly elevated when we combined the mTOR inhibitor rapamycin with alpelisib. Nevertheless, this combination was more effective than treatment with the same concentrations of either drug alone in terms of inhibition of proliferation. Supporting this finding, we detected a synergistic effect of rapamycin and alpelisib treatment on cell viability. In line with the findings of Keam et al., in head and neck cancer cell lines, we detected a reduction of proliferation using alpelisib at similar concentrations [21].

In the majority of cancers with mutated PI3K, the PI3K $\alpha$ isoform is activated [22]. Alpelisib is a selective PI3K $\alpha$ inhibitor [9]. As hypothesized, alpelisib inhibited phosphorylation and, therefore, activation of AKT in the lipoma cells. This also affected the downstream PI3K-pathway molecule ribosomal protein S6, which is phosphorylated by the ribosomal protein S6 kinase beta 1 (S6K1). S6K1 is known to be a key molecule in transcriptional regulation of cell cycle and cell size [23]. Alpelisib inhibited S6 phosphorylation to the same extent as direct mTOR inhibition through rapamycin. We found that after $48 \mathrm{~h}$ treatment with $100 \mu \mathrm{M}$ alpelisib, only approximately 1\% of cells showed S6 phosphorylation. When treating lipoma cells with rapamycin, we observed an increased phosphorylation of AKT, confirming earlier findings in lipoma cells [4]. This AKT activation induced by inhibition of the negative feedback regulation by mTORC1 [7] could be reversed when combining rapamycin with $10 \mu \mathrm{M}$ alpelisib. This indicates that resistance mechanisms occurring during rapamycin treatment of PHTS patients might be overcome when co-treating with alpelisib. Moreover, an inhibition of further upstream molecules of the PI3K pathway through alpelisib may overcome the limitations of targeting mTOR. PTEN directly antagonizes PI3K, and in patients with germline PTEN mutations, this leads to an activation of the whole pathway. PI3K inhibitors limit this pathway activation on the same level as PTEN, which might provide advantages over an inhibition further downstream.

Many cancer cells are known to rely on aerobic glycolysis as their primary source of energy generation. The PI3K pathway plays a major role in regulating this metabolic process [24]. To further dissect molecular causes for the observed growth arrest after alpelisib treatment, we quantified gene expression of the glucose transporter GLUT1 and the glycolysis enzyme PGK. Both were significantly reduced, indicating changes in glucose metabolism on the transcriptional level during alpelisib treatment, along with a reduction of proliferating cell nuclear antigen (PCNA) expression, a marker for proliferating cells. In patients, this might be advantageous to mainly target cells with a transformed metabolic profile, and therefore selectively inhibit malignancies.

To test alpelisib in a physiological model of lipoma adipocyte differentiation, we used 3D cultures of lipoma cells. Size of lipoma cell spheroids in 3D culture increased during 10 days in differentiation medium, as shown before [17], which is probably due to a cell volume increase because of lipid 
accumulation. This effect was not observed when treating lipoma spheroids with $10 \mu \mathrm{M}$ alpelisib, which, in contrast, led to a reduced spheroid size. This could result both from an inhibition of differentiation and from a reduction of cell size through downregulation of S6 phosphorylation [25]. In PHTS patients, a reduction in lipoma size without surgery could counteract disease progression, and therefore prevent life-threatening complications. mTOR is known to regulate adipocyte differentiation through PPAR $\gamma$, the master transcriptional regulator of adipogenesis [26]. Similar to rapamycin [27], we found that alpelisib reduced adipocyte differentiation in 2D lipoma cells culture as well. The differentiation markers PPAR $\gamma$, adiponectin, aP2, and FASN were downregulated.

We finally tested whether the attenuated adipocyte differentiation observed in alpelisib-treated lipoma cells was caused by preservation of stem cell characteristics. When checking gene expression of CD44 and CD90, markers present on adipose-derived mesenchymal stem cells, we found gene expression differences in differentiated lipoma cells that were alpelisib-treated compared to controls. We found that the stem cell marker CD90 was downregulated. CD90 downregulation is associated with senescence in mesenchymal stem cells [28]. In contrast, CD44 was upregulated. Although considered a mesenchymal stem cell marker [29], CD44 was also found to be a senescence-induced cell adhesion gene [30]. Supporting these data, we detected upregulation of CDKN2A ( $p 16)$ by alpelisib, both in differentiated and undifferentiated lipoma cells. Moreover, alpelisib enhanced $\beta$-galactosidase staining of lipoma cells. These findings indicate that alpelisib induced senescence both in PTEN haploinsufficient preadipocytes and differentiated adipocytes. In a mouse model for PROS syndrome, no induction of senescence or apoptosis was detected [8].

Alpelisib was successfully used to treat overgrowth of different tissues associated with activating PI3K mutations in PROS patients [8]. Since activating PI3K mutations and deactivating PTEN mutations both activate the PI3K-pathway, we hypothesize beneficial effects of alpelisib for PHTS patients as well. In our cell culture experiments, we indeed observed similar effects on cell viability in PROS and PHTS patients' lipoma cells. We found growth-inhibitory effects with PI3K-pathway inhibition and reduction in size of in vitro lipoma 3D models. The main adverse event found in clinical trials with alpelisib was hyperglycemia [10-12]. Alpelisib was tested in a set of pediatric patients with PROS where it was well tolerated, and side effects were reported to be mild and manageable [8]. We therefore consider alpelisib as a potential future alternative to rapamycin treatment or as an option for combination therapy with rapamycin for patients with PHTS-associated lipoma. As a next step, we propose testing of alpelisib in vivo. We will test effects of alpelisib on PTEN knockout and wildtype tissues in a conditional PTEN-knock-out mouse model and investigate the reversibility of these effects.

\section{Materials and Methods}

\subsection{Cell Culture and Adipocyte Differentiation}

We used cells of the stromal vascular fraction isolated from lipomas of three different pediatric PHTS and two PROS patients (Leipzig University ethical approval: no. 425-12-171220). Mutations were detected by Sanger sequencing [18], while the PTEN deletion seen in LipPD1 was analyzed by multiplex ligation-dependent probe amplification (MLPA) and array-based comparative genomic hybridization (Array-CGH) [4]. A reduction in PTEN mRNA and/or protein, as well as increased AKT phosphorylation, compared to PTEN wildtype controls was found [18]. Isolation and culture methods were described previously [4,18]. Table 1 contains a list of the lipoma cells used.

Table 1. Lipoma cells from pediatric PHTS and PROS patients [18].

\begin{tabular}{clcc}
\hline Name & Sex & Age at Resection & Mutation \\
\hline LipPD1 & male & 3 & Heterozygous deletion of PTEN exons 2-9 of 9 \\
LipPD2 & male & 3 & PTEN heterozygous point mutation (c.404T $>$ A, p.I135K) \\
LipPD3 & female & 4 & PTEN heterozygous point mutation (exon 1, c.76A $>$ C, p.T26P) \\
Lip3 & female & 14 & Mosaic PI3KCA mutation (10\%) (exon 10, c.1624G $>$ A, p.(Glu542Lys) \\
Lip4 & male & 13 & Mosaic PI3KCA mutation (30-40\%) (exon 8, c.1340_1366del, p.(Pro447_Leu455del) \\
\hline
\end{tabular}


For differentiation, we plated 13,000 lipoma cells $/ \mathrm{cm}^{2}$ in culture medium and changed medium to differentiation medium (DMEM/F12 containing $2 \mu \mathrm{mol} / \mathrm{L}$ rosiglitazone, $25 \mathrm{nmol} / \mathrm{L}$ dexamethasone, $0.5 \mathrm{mmol} / \mathrm{L}$ methylisobuthylxantine, $0.1 \mu \mathrm{mol} / \mathrm{L}$ cortisol, $0.01 \mathrm{mg} / \mathrm{mL}$ apotransferrin, $0.2 \mathrm{nmol} / \mathrm{L}$ triiodotyronin, and $20 \mathrm{nmol} / \mathrm{L}$ human insulin [31]) after $24 \mathrm{~h}$. Cells were incubated with $10 \mu \mathrm{M}$ alpelisib (Selleckchem, Munich, Germany) or solvent control (DMSO) in differentiation medium for 10 days. The medium was replaced every $72 \mathrm{~h}$. For lipid staining, cells were fixed in Roti-Histofix $4 \%$ (Carl Roth GmbH, Karlsruhe, Germany), washed with DPBS, and stained with Oil Red O solution $(0.03 \%$ in $60 \%$ isopropanol, Sigma, St. Louis, MO, USA) for $15 \mathrm{~min}$ at $37^{\circ} \mathrm{C}$ [32]. For transcriptional comparison to undifferentiated cells, these were kept in serum-free culture medium for 4 days.

A modified method according to Klingelhutz et al. was used for scaffold-free 3D cultures of lipoma cells [17]. To form spheroids, 10,000 cells per well were seeded into low attachment 96-well microplates (PS, U-bottom, clear, cellstar ${ }^{\circledR}$, cell-repellent surface, Greiner Bio-One, Kremsmünster, Austria) in $100 \mu \mathrm{l}$ differentiation medium and incubated for $24 \mathrm{~h}$. After $24 \mathrm{~h}$, spheroids were incubated with $10 \mu \mathrm{M}$ alpelisib or solvent control in differentiation medium for 10 days. Half of the medium was replaced every $72 \mathrm{~h}$. Microscope images were taken daily using the EVOS FL Auto 2 Cell Imaging System (Invitrogen; Thermo Fisher Scientifc, Inc., Waltham, MA, USA). Image analysis to determine the spheroid size was performed using ImageJ [33].

\subsection{Cell Viability/Proliferation}

For proliferation assays, cells were seeded at a density of 3000 cells/well $(24 \mathrm{~h})$ or 1500 cells/well (48-144 h) on 96-well plates and treated with different concentrations of alpelisib and/or rapamycin (both Selleckchem, Munich, Germany). Medium was replaced every $72 \mathrm{~h}$. Cell viability measures were performed using the Cell Proliferation Reagent WST-1 (Roche Diagnostics GmbH, Mannheim, Germany) according to the manufacturer's protocol. After WST-1 assay, cells were fixed and nuclei were stained with Hoechst 33342 (Sigma, Munich, Germany) for $5 \mathrm{~min}$ at a concentration of $10 \mu \mathrm{g} / \mathrm{ml}$ in DPBS. Hoechst fluorescence was detected at $455 \mathrm{~nm}$.

\subsection{Apotosis Assay}

For apoptosis detection, cells were seeded at a density of 1750 cells $/ \mathrm{cm}^{2}$ and treated with alpelisib/alpelisib+rapamycin for $72 \mathrm{~h}$. Then, $50 \mu \mathrm{M}$ perifosine (Selleckchem, Munich, Germany) was used as a positive control. The FITC-Annexin V Apoptosis Detection Kit I (BD Pharmingen, Franklin Lakes, NJ, USA) was used for annexinV-fluorescein isothiocyanate and propidium iodide staining of the trypsinized cells. Apoptosis was detected by flow cytometry.

\subsection{LDH Cytotoxcicity Assay}

For LDH cytotoxicity assays, cells were seeded at a density of 3000 cells/well on 96-well plates in culture medium. Cells were treated for $72 \mathrm{~h}$ with $50 \mu \mathrm{M}$ alpelisib, $10 \mathrm{nM}$ rapamycin, or a combination of both. LDH release was detected using the CyQUANT ${ }^{\mathrm{TM}}$ LDH Cytotoxicity Assay (Invitrogen; Thermo Fisher Scientifc, Inc., Waltham, MA, USA) according to the manufacturer's protocol.

\subsection{Western Blot Analysis}

For Western blot analysis, lipoma cells were seeded at a density of 10,000 cells $/ \mathrm{cm}^{2}$ in culture medium. Cells were incubated with different alpelisib and/or rapamycin concentrations for $24 \mathrm{~h}$. Proteins were extracted and immunoblotting was performed as described elsewhere [4]. We used $10 \mu \mathrm{g}$ protein per lane and incubated with primary antibodies (Cell Signaling Technology, Inc., Danvers, MA, USA) and secondary antibodies (Dako; Agilent Technologies, Inc., Santa Clara, CA, USA), according to Table 2. Glyceraldehyde-3-phosphate dehydrogenase (GAPDH) (Merck KGaA, Darmstadt, Germany) was used as loading control. 
Table 2. Antibodies used for Western blot $(\mathrm{Wb})$ and immunofluorescence staining (IF).

\begin{tabular}{cccc}
\hline Primary Antibody & Dilution & Supplier & Cat. no \\
\hline mTOR (7C10) Rabbit mAb & $1: 1000$ TBS-T 5\%BSA (Wb) & CST & $\# 2983$ \\
Phospho-mTOR (Ser2448) Rabbit mAb (D9C2) & $1: 1000$ TBS-T 5\%BSA (Wb) & CST & $\# 5536$ \\
AKT antibody Rabbit polyclonal Ab & $1: 1000$ TBS-T 5\%BSA (Wb) & CST & $\# 9272$ \\
Phospho-AKT (Thr308) (224F9) Rabbit mAb & $1: 500$ TBS-T 5\%BSA (Wb) & CST & $\# 4056$ \\
S6 ribosomal protein (5G10) Rabbit mAb & $1: 1000$ TBS-T 5\%BSA (Wb) & CST & $\# 2217$ \\
Phospho-S6 Ribosomal protein (Ser235/236) (D57.2.2E) & $1: 1000$ TBS-T 5\%BSA (Wb) & CST & $\# 4858$ \\
XP ${ }^{\circledR}$ Rabbit mAb & $1: 500$ IF-buffer (IF) & Merck & MAB374 \\
GAPDH (6C5) Mouse mAb & $1: 50,000$ TBS-T 5\% milk (Wb) & Dako & P0447 \\
KI-67 (MIB-1) Mouse mAb & $1: 200$ IF-buffer (IF) & Supplier & Cat. no \\
Secondary antibody & Dilution & Dako & P0447 \\
Polyclonal goat anti-rabbit immunoglobulin/HRP & $1: 2000$ TBS-T 5\% milk (Wb) & Dako & P0448 \\
Polyclonal goat anti-mouse immunoglobulin/HRP & $1: 2000$ TBS-T 5\% milk (Wb) & Invitrogen & A11001 \\
Alexa Fluor 488 goat anti-mouse IgG H+L & $1: 1000$ IF-buffer (IF) & Invitrogen & A11034 \\
Alexa Fluor 488 goat anti-rabbit IgG H+L & $1: 1000$ IF-buffer (IF) &
\end{tabular}

\subsection{Immunofluorescence Staining}

For immunofluorescence staining, cells were fixed in 4\% PFA after $48 \mathrm{~h}$ of alpelisib treatment. Cells were permeabilized and blocked in IF-buffer (DPBS + 5\% BSA + 0.3\% Tween20) for $1 \mathrm{~h}$ at RT and stained with pS6 or Ki-67 primary antibodies over night at $4{ }^{\circ} \mathrm{C}$ (Table 2). Cells were washed three times with IF-buffer and incubated with secondary antibodies (Invitrogen; Thermo Fisher Scientifc, Inc., Waltham, MA, USA) for $2 \mathrm{~h}$ at RT in the dark. We took microscope images using the EVOS FL Auto 2 Cell Imaging System (Invitrogen; Thermo Fisher Scientific, Inc., Waltham, MA, USA). Counting of nuclei (DAPI channel) and pS6/Ki-67 positive cells (GFP channel) was performed using the Celleste Image Analysis Software (Thermo Fisher Scientific).

\subsection{Reverse Transcription Quantitative PCR (RT-qPCR)}

For transcriptional analysis, we seeded $5000 \mathrm{cells} / \mathrm{cm}^{2}$ in culture medium and extracted mRNA after $24 \mathrm{~h}$ of treatment with $10 \mu \mathrm{M}$ alpelisib or solvent control. For transcriptional analysis on differentiation, cells were seeded at a density of $13,000 \mathrm{cells} / \mathrm{cm}^{2}$. Cells were kept in differentiation medium with or without $10 \mu \mathrm{M}$ alpelisib for 10 days before RNA was extracted. RNA extraction, reverse transcription, and qPCR were performed as previously described [18]. Table 3 contains a list of primers used for qPCR assays (Applied Biosystems; Thermo Fisher Scientifc, Inc.). Glucose transporter 1 (GLUT1), phosphoglycerate kinase (PGK), and Proliferating cell nuclear antigen (PCNA) mRNA was normalized to the housekeeper Tata box binding protein (TBP) mRNA. PPAR $\gamma$, adiponectin, aP2, FASN, p16, CD44, and CD90 mRNA were normalized to the housekeepers $\beta$-actin or HPRT mRNA.

Table 3. Primers used for RT-qPCR.

\begin{tabular}{|c|c|c|c|}
\hline Gene & Forward & Reverse & Probe \\
\hline$T B P$ & TTGTAAACTTGACCTAAAGACCATTGC & TTCGTGGCTCTCTTATCCTCATG & AACGCCGAATATAATCCCAAGCGGTTTG \\
\hline$\beta$-actin & CGA GCG CGG CTA CAG CTT & TGC TTG TGT TGG GTG GAT ATT G & TGG CCA CCG ACT CCT ACA AGG TTA CTC AC \\
\hline HPRT & GGC AGT ATA ATC CAA AGA TGG TCA A & GTC TGG CTT ATA TCC AAC ACT TCG T & CAA GCT TGC TGG TGA AAA GGA CCC C \\
\hline GLUT1 & TGGCATCAACGCTGTCTTCT & AGCCAATGGTGGCATACACA & \\
\hline PGK & GAATGGGAAGCTTTTGCCCG & GCAGTGTCTCCACCACCTATG & \\
\hline PCNA & CTAAAATGCGCCGGCAATGA & TCTCCTGGTTTGGTGCTTCA & \\
\hline Adiponectin & GGC CGT GAT GGC AGA GAT & CCT TCA GCC CCG GGT ACT & CGATGTCTCCСTTAGGACCAATAAGACCTGG \\
\hline aP2 & GCTTTTGTAGGTACCTGGAAACTTG & ACA CTG ATG ATC ATG TTA GGT TTG G & CCTGGTGGCAAAGCCCACTCCTCAT \\
\hline PPAR $\gamma$ & GATCCAGTGGTTGCAGATTACAA & GAGGGAGTTGGAAGGCTCTTC & TGACCTGAAACTTCAAGAGTACCAAAGTGCAA \\
\hline FASN & GGCAAATTCGACCTTTCTCAGA & GGACCCCGTGGAATGTCA & CACCCGCTCGGCATGGCTATCTT \\
\hline p16 & CTTCGGCTGACTGGCTGG & TCATCATGACCTGGATCGGC & \\
\hline$C D 44$ & Predesigned assay (ID: Hs01075864_m1) & & \\
\hline CD90 & Predesigned assay (ID: Hs00264235_s1) & & \\
\hline
\end{tabular}

\subsection{Senescence $\beta$-Galactosidase Staining}

To detect senescence, we seeded 2000 cells/well on 96-well plates in culture medium. After $72 \mathrm{~h}$ of treatment with $10 \mu \mathrm{M}$ alpelisib or solvent control, we performed fixation and senescent cell staining using the Senescence $\beta$-Galactosidase Staining Kit (Cell Signaling Technology, Inc., Danvers, MA, USA) 
according to the manufacturer's protocol. We used $60 \mu \mathrm{l} \beta$-galactosidase staining solution per well and after overnight incubation, we added $50 \mu \mathrm{L}$ Hoechst in DPBS $(1 \mathrm{ng} / \mathrm{mL})$ and took microscope images using the EVOS FL Auto 2 Cell Imaging System (pictures of 5\% of the well area). We counted nuclei (DAPI channel) with the Celleste Image Analysis Software (Thermo Fisher Scientific) and $\beta$-galactosidase positive cells (blue, phase contrast) using ImageJ [33].

\subsection{Statistical Analysis}

Means of at least three independent experiments were statistically analyzed using GraphPad Prism 6 software (GraphPad Software, Inc., La Jolla, CA, USA). For comparison of two conditions, means of independent experiments were compared via unpaired Student's $t$-test. For multiple comparisons, we used one- or two-way analysis of variance (ANOVA), followed by a post-hoc Tukey's multiple comparisons test (one-way ANOVA) or Dunnett's multiple comparisons test (two-way ANOVA). To determine the significance of fold changes, we used one-sample $t$-tests of the $\log$ (fold change) and compared to the hypothetical value 0 [34]. To calculate $\mathrm{IC}_{50}$ values, we used GraphPad Prism 6 (nonlinear fit, $\log$ (inhibitor) vs. response, least squares fit, standard slope model). Isobologram analysis [13] was done using the CalcuSyn software program.

\section{Conclusions}

Lipomatosis in pediatric PHTS patients is a rare condition, but nevertheless, can affect individuals in a life-threatening manner due to limited treatment options. In this research project, we tested the PI3K inhibitor alpelisib on PTEN-haploinsufficient lipoma cells from PHTS patients. We found that alpelisib inhibited cellular growth and reduced the size of 3D lipoma cell cultures, although alpelisib did not induce apoptosis. In contrast to rapamycin, alpelisib inhibited activation of AKT, promising to overcome drug resistance mechanisms occurring during rapamycin treatment in PHTS patients [4].

Supplementary Materials: The following are available online at http://www.mdpi.com/2072-6694/11/10/1586/s1, Figure S1: Combination index for alpelisib and rapamycin, Figure S2: Immunofluorescence staining of LipPD2 and LipPD3 cells after $72 \mathrm{~h}$ of alpelisib treatment Figure S3: Western blot analysis of LipPD2 cells after $24 \mathrm{~h}$ treatment with alpelisib and/or rapamycin, Figure S4: Western blot analysis of LipPD3 cells after $24 \mathrm{~h}$ treatment with alpelisib and/or rapamycin, Figure S5: Western blots after $24 \mathrm{~h}$ treatment with alpelisib and/or rapamycin in LipPD1, Figure S6: Western blots after $24 \mathrm{~h}$ treatment with alpelisib and/or rapamycin in LipPD2 and LipPD3 \#1, Figure S7: Western blots after $24 \mathrm{~h}$ treatment with alpelisib and/or rapamycin in LipPD3 (\#2 and \#3), Figure S8: RT-qPCR of Fatty acid synthase (FASN) gene from LipPD1 cells after 10 days of differentiation with or without $10 \mu \mathrm{M}$ alpelisib, Figure S9: $\beta$-galactosidase senescence staining of lipoma cells after $72 \mathrm{~h}$ alpelisib treatment, Figure S10: RT-qPCR of senescence, stem cell and adipogenesis marker genes from LipPD1-3 cells before or after 10 days of differentiation with or without $10 \mu \mathrm{M}$ alpelisib, Table S1: IC50 values for $72 \mathrm{~h}$ alpelisib treatment in different lipoma cells, Table S2: Densitometric analysis of LipPD1 Western blots, Table S3: Densitometric analysis of LipPD2 and LipPD3 Western blots.

Author Contributions: Conceptualization, A.G., A.S.K., and W.K.; methodology, A.G., A.S.K., M.P., and A.K.; validation, A.G., A.S.K., and A.A.; formal analysis, A.S.K., A.A., and M.C.; investigation, A.A. and A.S.K.; resources, A.G., M.P., A.K., and W.K.; writing—original draft preparation, A.S.K. and M.C.; writing-review and editing, A.G.; visualization, A.S.K. and M.C.; supervision, A.G.; project administration, A.G. and W.K.; funding acquisition, A.A., M.P., A.G., and W.K.

Funding: This research was funded by the Deutsche Forschungsgemeinschaft (DFG, German Research Foundation) 209933838 - SFB 1052), Federal Ministry of Education and Research (BMBF), Germany, FKZ: 01EO1501, IFB project AD2-7105 and ERASMUS+, grant number 2018-1-BE01-KA103-038469. We acknowledge support from the German Research Foundation (DFG) and Leipzig University within the program of Open Access Publishing.

Acknowledgments: We want to thank Sandy Richter for the technical support in the laboratory, and Tomàs Suchý and Sören Pietsch for the help with ImageJ.

Conflicts of Interest: The authors declare no conflicts of interest. The funders had no role in the design of the study; in the collection, analyses, or interpretation of data; in the writing of the manuscript; or in the decision to publish the results. 


\section{References}

1. Blumenthal, G.M.; Dennis, P.A. PTEN hamartoma tumor syndromes. Eur. J. Hum. Genet. 2008, 16, 1289-1300. [CrossRef] [PubMed]

2. Gorlin, R.J.; Cohen, M.M.; Condon, L.M.; Burke, B.A. Bannayan-Riley-Ruvalcaba syndrome. Am. J. Med. Genet. 1992, 44, 307-314. [CrossRef] [PubMed]

3. Marsh, D.J.; Trahair, T.N.; Martin, J.L.; Chee, W.Y.; Walker, J.; Kirk, E.P.; Baxter, R.C.; Marshall, G.M. Rapamycin treatment for a child with germline PTEN mutation. Nat. Rev. Clin. Oncol. 2008, 5, 357. [CrossRef] [PubMed]

4. Schmid, G.L.; Kässner, F.; Uhlig, H.H.; Körner, A.; Kratzsch, J.; Händel, N.; Zepp, F.-P.; Kowalzik, F.; Laner, A.; Starke, S.; et al. Sirolimus treatment of severe PTEN hamartoma tumor syndrome: Case report and in vitro studies. Pediatr. Res. 2014, 75, 527-534. [CrossRef]

5. Vanhaesebroeck, B.; Stephens, L.; Hawkins, P. PI3K signalling: The path to discovery and understanding. Nat. Rev. Mol. Cell. Biol. 2012, 13, 195-203. [CrossRef]

6. Bazzichetto, C.; Conciatori, F.; Pallocca, M.; Falcone, I.; Fanciulli, M.; Cognetti, F.; Milella, M.; Ciuffreda, L. PTEN as a Prognostic/Predictive Biomarker in Cancer: An Unfulfilled Promise? Cancers 2019, 11, 435. [CrossRef]

7. O’Reilly, K.E.; Rojo, F.; She, Q.-B.; Solit, D.; Mills, G.B.; Smith, D.; Lane, H.; Hofmann, F.; Hicklin, D.J.; Ludwig, D.L.; et al. mTOR inhibition induces upstream receptor tyrosine kinase signaling and activates Akt. Cancer Res. 2006, 66, 1500-1508. [CrossRef]

8. Venot, Q.; Blanc, T.; Rabia, S.H.; Berteloot, L.; Ladraa, S.; Duong, J.-P.; Blanc, E.; Johnson, S.C.; Hoguin, C.; Boccara, O.; et al. Targeted therapy in patients with PIK3CA-related overgrowth syndrome. Nature 2018, 558, 540. [CrossRef]

9. Furet, P.; Guagnano, V.; Fairhurst, R.A.; Imbach-Weese, P.; Bruce, I.; Knapp, M.; Fritsch, C.; Blasco, F.; Blanz, J.; Aichholz, R.; et al. Discovery of NVP-BYL719 a potent and selective phosphatidylinositol-3 kinase alpha inhibitor selected for clinical evaluation. Bioorg. Med. Chem. Lett. 2013, 23, 3741-3748. [CrossRef]

10. Jain, S.; Santa-Maria, C.A.; Rademaker, A.; Giles, F.J.; Cristofanilli, M.; Gradishar, W.J. Phase I study of alpelisib (BYL-719) and T-DM1 in HER2-positive metastatic breast cancer after trastuzumab and taxane therapy. JCO 2017, 35, 1026. [CrossRef]

11. André, F.; Ciruelos, E.M.; Rubovszky, G.; Campone, M.; Loibl, S.; Rugo, H.S.; Iwata, H.; Conte, P.; Mayer, I.A.; Kaufman, B.; et al. LBA3_PRAlpelisib (ALP) + fulvestrant (FUL) for advanced breast cancer (ABC): Results of the phase III SOLAR-1 trial. Ann. Oncol. 2018, 29. [CrossRef]

12. Juric, D.; Rodon, J.; Tabernero, J.; Janku, F.; Burris, H.A.; Schellens, J.H.M.; Middleton; Berlin, J.; Schuler, M.; Gil-Martin, M.; et al. Phosphatidylinositol 3-Kinase $\alpha$-Selective Inhibition With Alpelisib (BYL719) in PIK3CA-Altered Solid Tumors: Results From the First-in-Human Study. J. Clin. Oncol. 2018, 36, 1291-1299. [CrossRef] [PubMed]

13. Chou, T.-C.; Talalay, P. Quantitative analysis of dose-effect relationships: The combined effects of multiple drugs or enzyme inhibitors. Adv. Enzyme Regul. 1984, 22, 27-55. [CrossRef]

14. Wang, G.; Cao, X.; Lai, S.; Luo, X.; Feng, Y.; Xia, X.; Yen, P.M.; Gong, J.; Hu, J. PI3K stimulates DNA synthesis and cell-cycle progression via its p55PIK regulatory subunit interaction with PCNA. Mol. Cancer Ther. 2013, 12, 2100-2109. [CrossRef] [PubMed]

15. Montessuit, C.; Thorburn, A. Transcriptional Activation of the Glucose Transporter GLUT1 in Ventricular Cardiac Myocytes by Hypertrophic Agonists. J. Biol. Chem. 1999, 274, 9006-9012. [CrossRef] [PubMed]

16. Joshi, S.; Singh, A.R.; Durden, D.L. MDM2 regulates hypoxic hypoxia-inducible factor $1 \alpha$ stability in an E3 ligase, proteasome, and PTEN-phosphatidylinositol 3-kinase-AKT-dependent manner. J. Biol. Chem. 2014, 289, 22785-22797. [CrossRef]

17. Klingelhutz, A.J.; Gourronc, F.A.; Chaly, A.; Wadkins, D.A.; Burand, A.J.; Markan, K.R.; Idiga, S.O.; Wu, M.; Potthoff, M.J.; Ankrum, J.A. Scaffold-free generation of uniform adipose spheroids for metabolism research and drug discovery. Sci. Rep. 2018, 8, 523. [CrossRef]

18. Kässner, F.; Sauer, T.; Penke, M.; Richter, S.; Landgraf, K.; Körner, A.; Kiess, W.; Händel, N.; Garten, A. Simvastatin induces apoptosis in PTEN-haploinsufficient lipoma cells. Int. J. Mol. Med. 2018, 41, 3691-3698. [CrossRef] 
19. Tang, H.; Xue, G. Major Physiological Signaling Pathways in the Regulation of Cell Proliferation and Survival. In Mechanisms of Drug Resistance in Cancer Therapy; Mandalà, M., Romano, E., Eds.; Springer: Cham, Switzerland, 2018; pp. 13-30. ISBN 978-3-030-10507-5.

20. Maiuri, T.; Ho, J.; Stambolic, V. Regulation of adipocyte differentiation by distinct subcellular pools of protein kinase B (PKB/Akt). J. Biol. Chem. 2010, 285, 15038-15047. [CrossRef]

21. Keam, B.; Kim, S.; Ahn, Y.-O.; Kim, T.M.; Lee, S.-H.; Kim, D.-W.; Heo, D.S. In vitro anticancer activity of PI3K alpha selective inhibitor BYL719 in head and neck cancer. Anticancer Res. 2015, 35, 175-182.

22. Thorpe, L.M.; Yuzugullu, H.; Zhao, J.J. PI3K in cancer: Divergent roles of isoforms, modes of activation, and therapeutic targeting. Nat. Rev. Cancer 2015, 15, 7-24. [CrossRef] [PubMed]

23. Fingar, D.C.; Blenis, J. Target of rapamycin (TOR): An integrator of nutrient and growth factor signals and coordinator of cell growth and cell cycle progression. Oncogene 2004, 23, 3151. [CrossRef] [PubMed]

24. Heiden, M.G.V.; Cantley, L.C.; Thompson, C.B. Understanding the Warburg Effect: The Metabolic Requirements of Cell Proliferation. Science 2009, 324, 1029-1033. [CrossRef] [PubMed]

25. Zhang, H.; Stallock, J.P.; Ng, J.C.; Reinhard, C.; Neufeld, T.P. Regulation of cellular growth by the Drosophila target of rapamycin dTOR. Genes Dev. 2000, 14, 2712-2724. [CrossRef] [PubMed]

26. Zhang, H.H.; Huang, J.; Düvel, K.; Boback, B.; Wu, S.; Squillace, R.M.; Wu, C.-L.; Manning, B.D. Insulin Stimulates Adipogenesis through the Akt-TSC2-mTORC1 Pathway. PLoS ONE 2009, 4, e6189. [CrossRef]

27. Cho, H.J.; Park, J.; Lee, H.W.; Lee, Y.S.; Kim, J.B. Regulation of adipocyte differentiation and insulin action with rapamycin. Biochem. Biophys. Res. Commun. 2004, 321, 942-948. [CrossRef]

28. Martini, H.; Iacovoni, J.S.; Maggiorani, D.; Dutaur, M.; Marsal, D.J.; Roncalli, J.; Itier, R.; Dambrin, C.; Pizzinat, N.; Mialet-Perez, J.; et al. Aging induces cardiac mesenchymal stromal cell senescence and promotes endothelial cell fate of the CD90 + subset. Aging Cell 2019, e13015. [CrossRef]

29. Ramos, T.L.; Sánchez-Abarca, L.I.; Muntión, S.; Preciado, S.; Puig, N.; López-Ruano, G.; Hernández-Hernández, Á.; Redondo, A.; Ortega, R.; Rodríguez, C.; et al. MSC surface markers (CD44, CD73, and CD90) can identify human MSC-derived extracellular vesicles by conventional flow cytometry. Cell Commun. Signal. 2016, 14. [CrossRef]

30. Mun, G.I.; Boo, Y.C. Identification of CD44 as a senescence-induced cell adhesion gene responsible for the enhanced monocyte recruitment to senescent endothelial cells. Am. J. Physiol. Heart Circ. Physiol. 2010, 298, H2102-H2111. [CrossRef]

31. Fischer-Posovszky, P.; Newell, F.S.; Wabitsch, M.; Tornqvist, H.E. Human SGBS Cells-A Unique Tool for Studies of Human Fat Cell Biology. Obes. Facts 2008, 1, 184-189. [CrossRef]

32. Rockstroh, D.; Löffler, D.; Kiess, W.; Landgraf, K.; Körner, A. Regulation of human adipogenesis by miR125b-5p. Adipocyte 2016, 5, 283-297. [CrossRef] [PubMed]

33. Schneider, C.A.; Rasband, W.S.; Eliceiri, K.W. NIH Image to ImageJ: 25 years of Image Analysis. Nat. Methods 2012, 9, 671-675. [CrossRef] [PubMed]

34. Tsai, C.-A.; Chen, Y.-J.; Chen, J.J. Testing for differentially expressed genes with microarray data. Nucleic Acids Res. 2003, 31, e52. [CrossRef] [PubMed]

(C) 2019 by the authors. Licensee MDPI, Basel, Switzerland. This article is an open access article distributed under the terms and conditions of the Creative Commons Attribution (CC BY) license (http://creativecommons.org/licenses/by/4.0/). 